\title{
Effect of different slaughterhouses on carcass and meat quality of pigs
}

\author{
D.C.A. Kalubowila ${ }^{1 *}$ and P.H.G.J. De Silva ${ }^{2}$
}

\begin{abstract}
The issue of meat quality has become a major concern in the swine industry of Sri Lanka. The impact of the condition of slaughterhouses on carcass and meat quality of pigs was studied in two different commercial slaughterhouses (SH), i.e. SH-A: HACCP certified with electrical stunning and SH-B: conventional slaughter system with mechanical stunning. Feed withdrawal, transport and lairage were standardized for each batch, which did not differ between slaughterhouses. Three batches of 60 Large White $\times$ Land Race crossbred pigs (live weight $86 \pm 6.9 \mathrm{~kg}$ ) were purchased from commercial farms, randomly divided into two groups and delivered to two slaughterhouses. Dressing percentage, time taken for animal to be unconscious, bleeding time, injuries, bruising, blood spots in meat, blood aspiration in lungs, water holding capacity (WHC), carcass temperature, $\mathrm{pH}$ at 45 minutes of post-slaughter, the total plate count (TPC), and microbial counts of Escherichia coli, Staphylococcus aureus and Salmonella spp were measured. Stunning time, bleeding time, temperature, blood aspiration in lungs, injuries, bruising and meat blood spots were significantly higher $(p<0.05)$ in SH-B than in the SH-A. Dressing percentage and carcass weight were not significantly different $(p>0.05)$ between the two slaughter houses. The microbial counts significantly differed $(\mathrm{p}<0.05)$ between slaughterhouses. The TPC and counts of $E$ coil and S. aureus between SH-A and SH-B were 4.41 vs 5.86, 2.37 vs 3.69 and 0.22 vs 2.35 log $\mathrm{CFU} / \mathrm{cm}^{2}$, respectively $(\mathrm{p}<0.05)$. However, Salmonella were not present in both slaughterhouses. The SH-B produced an inferior quality meat compared to $\mathrm{SH}-\mathrm{A}$, where meat of SH-B had a lower $\mathrm{pH}_{45 \min }(\mathrm{A}: 6.45 \pm 0.02 \mathrm{vs}$. $\mathrm{B}: 6.20 \pm 0.01)$, and exhibited higher carcass temperature and lower WHC. The results suggested that the slaughter house $A$ with HACCP certification was far better than the slaughter house B in terms of carcass and meat quality of pigs.
\end{abstract}

Keywords: Carcass quality, meat quality, pork, slaughterhouse, stunning method

\section{Introduction}

A slaughterhouse (abattoir) is the place where animals are slaughtered to produce meat for human consumption. The methods used to handle and process pigs in slaughterhouse are well-known to have a significant impact on the animal welfare, carcass and meat quality of pigs, and the safety of personnel operating in the system (Gispert et al., 2000; Mlynek et al., 2012). Prior to slaughter, the first step in the transformation of pigs into edible pork involves stunning. However, stunning method is not a legal requirement in Sri Lanka. At

\footnotetext{
${ }^{1}$ ADM Food Products (Pvt) Ltd., Katukenda, Badalgama, Sri Lanka

${ }^{2}$ Post Graduate Institute Agriculture, University of Peradeniya, Sri Lanka

* Corresponding Author: antonkalubo@gmail.com
} 
present, both mechanical stunning (MS) and electrical stunning (ES) methods are used to slaughter pigs in Sri Lanka. Stress immediately prior to slaughter, method of stunning, bleeding, scalding and evisceration plays an important role in conversion of muscle to meat (Brown et al., 1998; Velarde et al., 2000).

Damages such as bruising, hemorrhages, skin blemishes, blood splash and broken bones are common occurrences found on carcasses due to improper handling of pigs. When such conditions occur, skin and affected parts of the carcass need to be trimmed off during processing. Trimming of the affected parts of the carcass will reduce meat yield and value, and increase processing time. Un-trimmed parts have poor appearance and can serve as substrates for microbial growth causing meat to spoil earlier than the normal. Broken bones may cause bone splinters in meat and this is hazardous to the consumer. The most important single defect of pork meat is pale, soft and exudative (PSE) condition representing a major problem to the pork industry (Golding et al., 2010). Poor processing characteristics and appearance make pork meat unacceptable to both processors and consumers.

Appropriate pre-slaughter handling and slaughtering method of pigs are therefore important, in terms of animal and carcass and meat quality of pigs, and is consequently linked to economic implications for the processor. A study was thus conducted to investigate the effect of pre-slaughter handling and method of slaughtering on carcass and meat quality of pigs at two different commercial slaughterhouses in Sri Lanka.

\section{Materials and Methods}

Three batches of 60 Large White $\times$ Land Race crossbred pigs were purchased from commercial farms. Within a batch, pigs were enrolled from the same farm and the animals had the same genetic background and similar live weight (86 $\mathrm{kg} \pm 6.9)$. Each batch was randomly divided into two groups and sent to two slaughterhouses (SH-A: HACCP certified with electrical stunning, SH-B: conventional slaughter system with mechanical stunning) on consecutive days. Feed withdrawal, transport (duration and loading density) and the period between arrival at the slaughterhouse and slaughter was standardized for each batch, which did not differ between the two slaughterhouses within the same batch. Proportion of sows and castrated males was equal across slaughter houses. Live weight, carcass weight, dressing percentage, stunning time, bleeding time, blood aspiration in lungs, injuries, bruising, physical defects, colour of meat and blood spots in meat were determined as physical parameters. Carcass temperature was measured by a digital thermometer (TESTO106), pH by using a digital pH meter (Checkit Micro pH WP 01) and Water Holding Capacity (WHC) by the centrifuging method (Kristensen and Purslow, 2001). The experimental meat samples were analyzed for Staphylococcus aureus on Baird-Parker medium spread plates incubated at $37{ }^{\circ} \mathrm{C}$, Escherichia coli on 
petirifilm ${ }^{\mathrm{TM}} \mathrm{E}$. coli count plate incubated at $35^{\circ} \mathrm{C}$, and total place count (TPC) on petirifilm ${ }^{\mathrm{TM}}$ aerobic count plate incubated at $37^{\circ} \mathrm{C}$, while Salmonella spp. was determined according to the method proposed by Gray and Patrick (1995). The data were analyzed by MINITAB ver. 14 using two-sample t-test $p=0.05$.

\section{Results and Discussion}

The live weight, carcass weight and chilled-carcass weight, and the dressing percentage were not significantly different $(p>0.05)$ between the two slaughterhouses (Table 1). The SH-A had significantly short stunning time (39.44 $\mathrm{s} ; \mathrm{p}<0.05)$ and bleeding time (46.6 s; $\mathrm{p}<0.05)$ than those of SH-B (141.12 s and 78 $\mathrm{S}$, respectively) (Figure 1). Electrical stunning was practiced at SH-A sending 220230 Volts via brain of the animal in 10-15 seconds. Damages to the carcasses were minimal by this method and it facilitated full bleeding, and increased the working efficiency of slaughter house. The SH-B used mechanical stunning and the carcasses were lying on the slaughterhouse floor while animals were bleeding and during the whole process. The technique used in SH-B increased the bleeding time of pigs due to cardiac arrest resulted in by excessive preslaughter stresses caused by mechanical stunning.

Table 1. Effect of different slaughter house on carcass characteristics of pigs

\begin{tabular}{lccccc}
\hline Traits & SH-A & SH- B & Mean & SE & P value \\
\hline Live weight (kg) & $90.9^{\mathrm{a}}$ & $89.75^{\mathrm{a}}$ & 90.32 & 0.5 & 0.47 \\
Hot carcass weight $(\mathrm{kg})$ & $72.29^{\mathrm{a}}$ & $73.07^{\mathrm{a}}$ & 72.68 & 0.6 & 0.43 \\
Chilled carcass weight $(\mathrm{kg})$ & $71.21^{\mathrm{a}}$ & $70.95^{\mathrm{a}}$ & 71.08 & 0.4 & 0.14 \\
Dressing percentage (hot) & $79.53^{\mathrm{a}}$ & $81.42^{\mathrm{a}}$ & 80.47 & 0.7 & 0.22 \\
\hline
\end{tabular}

SH: slaughterhouse, SE: standard error of the mean

A higher incidence of bruises, injuries, hemorrhages, physical defects and skin blemishes in carcasses, blood aspiration in lungs, heat, liver and blood spot on meat was observed in SH-B $(p<0.05)$ compared to SH-A (Figure 2). This was mainly due to the physiological stress of stunning-induced capillary rupture resulting in from increased blood pressure immediately after stunning in SH-B. These were signs of poor bleeding, high residual blood, and poor pre-slaughter handling of pigs. Hence, the method adopted by SH-B could increase downgrading problems.

Forty five minutes after stunning, $\mathrm{pH}$ of the pork meat was significantly higher $(p<0.05)$ at the SH-A (6.45) compared to that of SH-B (6.2). Pigs slaughtered at $\mathrm{SH}-\mathrm{B}$ exhibited significantly higher $(\mathrm{p}<0.05)$ carcass temperature $\left(37.40^{\circ} \mathrm{C}\right)$ with a lower WHC ( $53.90 \%$; $\left.p<0.05\right)$. High carcass temperature of pigs slaughtered at SH-B could be due to the severe stress and impulsive behavior during stunning. Grandin (1994) reported that high "excitability" created by pre- 
slaughter stress during stunning would result in elevated glycolytic metabolism in pigs just prior to slaughter. This would lead to higher heat production and hence, elevate body temperature of the pig. Increased carcass temperature has an effect on microbial growth of carcasses. Warriss (1994) reported that slaughtered animals within one hour had a body temperature ranging between 37 to $39^{\circ} \mathrm{C}$.

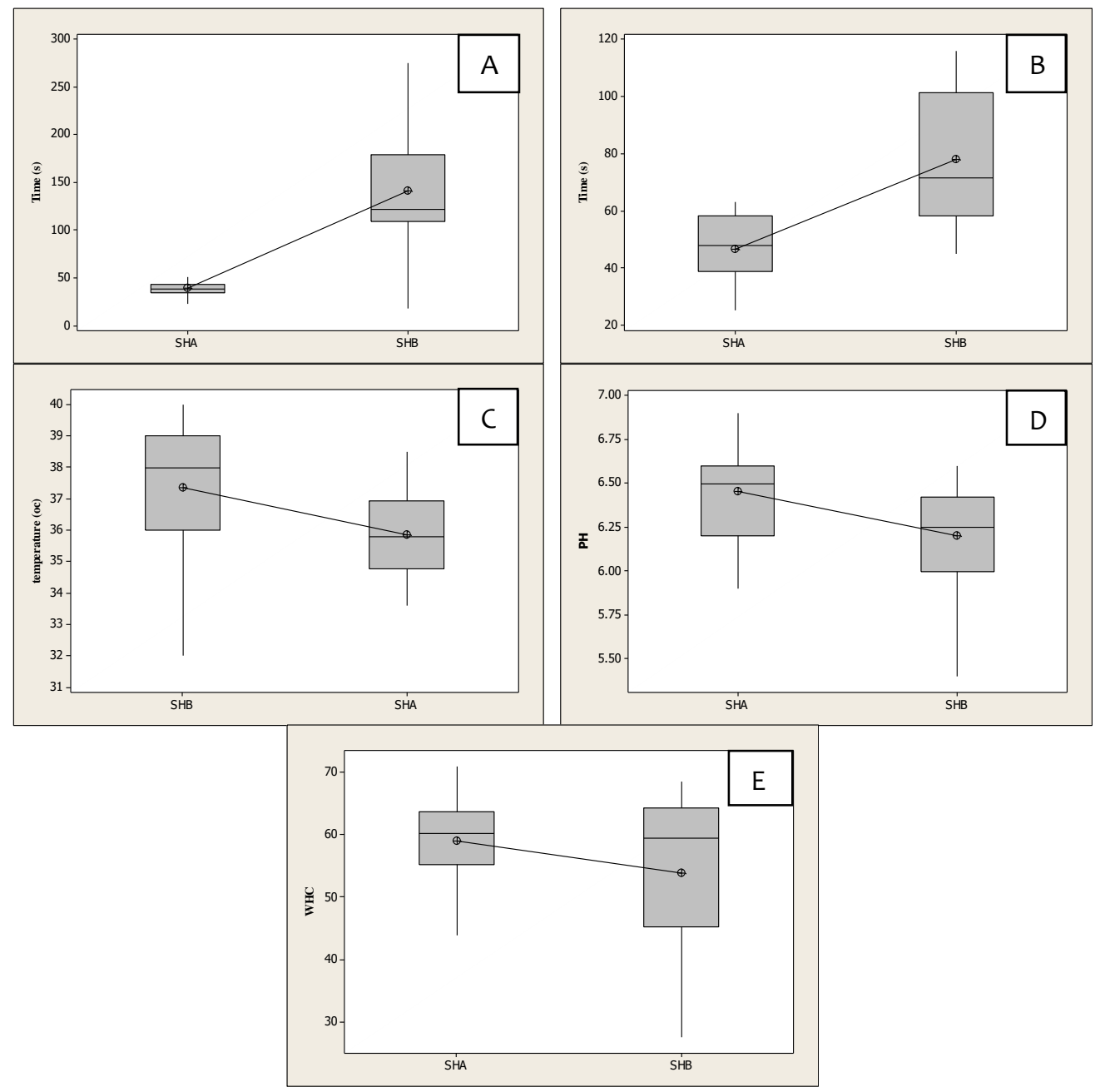

Figure 2. Stunning Time (a), bleeding time (b), carcass temperature(c), pH (d) and WHC (e) influenced by two slaughterhouses

Moreover, Lawrie (1998) stated that the rate of biochemical reactions in the muscle was positively correlated with carcass temperature. Van der Wal et al. (1997) and Hambrecht et al. (2004) indicated that a faster pH fall in the early post mortem has resulted in negative consequences in drip loss, WHC and pork color. Furthermore, some authors have proposed that a combination of rapid 
$\mathrm{pH}$ drop and high temperature has resulted in denaturation of muscle proteins, which bind water leading to the reduced WHC (Swatland, 1993; Van der Wal et al., 1997; Adzitey, 2011).

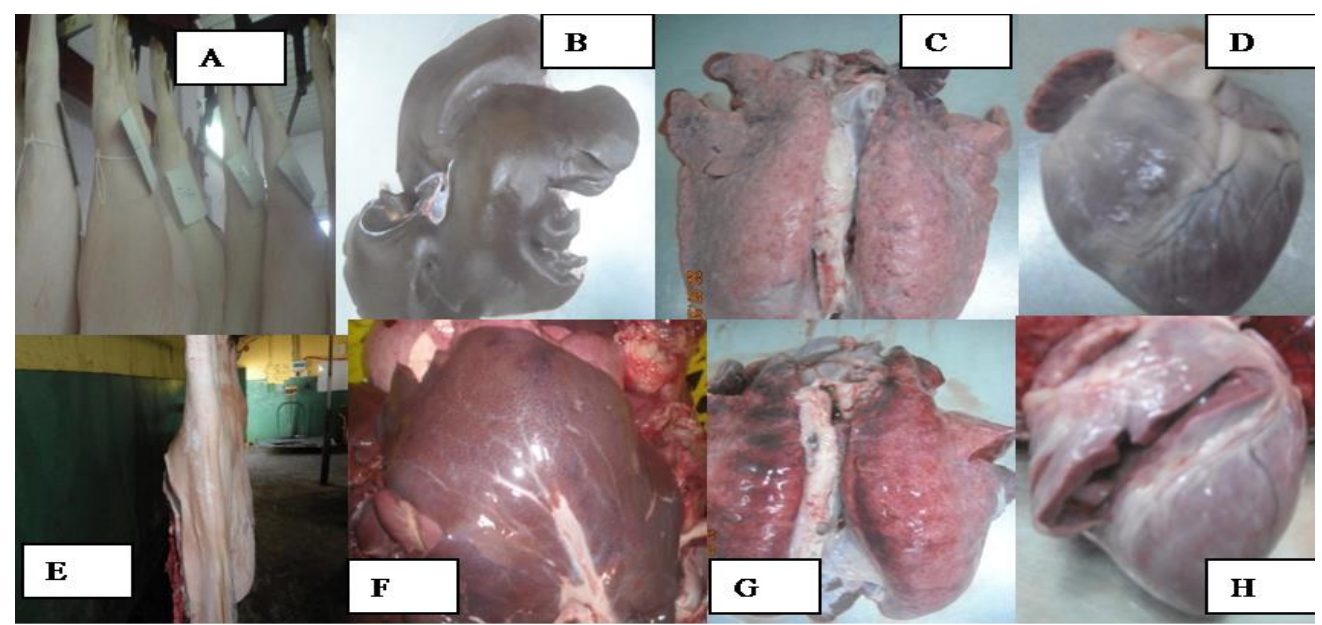

Figure 1. Macrophotography of the pig carcass and internal organs (A: SH-A carcass; $\mathrm{B}$ : SH-A liver; C: SH-A lungs; D: SH-A heart; E: SH-B carcass; F: SH-B liver; G: SH-B lungs; H: SH-B heart)

There was a significantly high levels $(\mathrm{p}<0.05)$ of TPC, E. coli and Staphylococcus count in SH-B (5.86, 3.69 and $2.35 \mathrm{log} \mathrm{CFU} / \mathrm{cm}^{2}$, respectively) than SH-A (4.41, 2.37, $0.22 \log \mathrm{CFU} / \mathrm{cm}^{2}$, respectively). However, Salmonella was not present in both systems. These results may attribute to the improper bleeding causing more blood to retain in the carcass. The bacterial count was positively affected by the amount of residual blood left in the carcass. Furthermore, the unhygienic condition, slaughtering malpractices and poor slaughterhouse management had an effect on high microbial count in SH-B.

\section{Conclusion}

Operations at slaughterhouses evaluated markedly influenced the carcass and meat quality of pork, independent of the pre-slaughter factors such as genetics, transport and lairage. The carcass and meat quality of pigs, which were obtained from SH-A with HACCP certification was better than SH-B. Hence, it could be concluded that better carcass and meat quality could be achieved by improving conventional slaughter houses to HACCP certified level.

\section{References}

Adzitey, F. (2011): Effect of pre-slaughter animal handling on carcass and meat quality, International Food Research Journal, 18: 485 -491. 
Brown, S.N., Warriss, P.D., Nute, G. R., Edwards, J.E., and Knowles, T.G. (1998): Meat quality in pigs subjected to minimal pre-slaughter stress. Meat Science, 49: 257265.

Gispert, M., Faucitano, L., Oliver, M.A., Gua rdia, M.D., Coll, C., Siggens, K., Harvey, K. and Diestre, A. (2000): A survey of pre-slaughter conditions, halothane gene frequency, ad carcass and meat quality in five Spanish pig commercial abattoirs. Meat Science, 55: 97-106.

Golding M.J.D., Showers C.D., Shand P.J. and Rosser B.W.C. (2010): Muscle fiber type and the occurrence of pale, soft, exudative pork, Journal of Muscle Foods 21(3): 484-498

Grandin, T. (1994): Methods to reduce PSE and blood splash. In: Proceedings Allen D. Leman Swine Conference, University of MN. pp 206-209.

Gray, L.D. and Patrick, R. (1995): Escherichia, salmonella, shigella and yersina in manual of clinical microbiology. pp 450-456. American Society for Microbiology, Washington, D.C.

Hambrecht E., Eissen, J.J., Nooijen, R.I.J., Ducro, B.J., Smits, C.H.M., Den Hartog, L.A. and Verstegen, M.W.A. (2004): Pre-slaughter stress and muscle energy largely determine pork quality at two commercial processing plants. Journal of Animal Science, 82:1401-1409

Kristensen, L., and Purslow, P.P. (2001): The effect of ageing on the water-holding capacity of pork: role of cytoskeletal proteins. Meat Science, 58:17-23

Lawrie, R.A. (1998): Lawrie's Meat Science ( $6^{\text {th }}$ Ed). Cambridge, England: Woodhead Technomic Publishing Ltd.

Swatland, H.J. (1993): Growth physiology and post-mortem metabolism in porcine muscle. In: Pork Quality: Genetic and Metabolic Factors. (Eds: E. Puolanne, D.I. Demeyer, M. Ruusunen and S. Ellis). pp. 115-139. CAB International, UK

Van der Wal, P.G., Engel, B. and Hulsegge, B. (1997): Causes for variation in pork quality. Meat Science, 46:319-327

Velarde, A., Gispert, M., Faucitano, L., Manteca, X. and Diestre, A. (2000): The effect of stunning method on the incidence of PSE meat and haemorrhages in pork carcasses. Meat Science, 55:309-314.

Warriss, P.D., Brown, S.N., Adams, S.J.M. and Corlett, I.K. (1994): Relationships between subjective and objective assessments of stress at slaughter and meat quality in pigs. Meat Science 38: 329-340. 